\title{
Mucosal bridge formation in a patient with esophageal epidermoid metaplasia
}

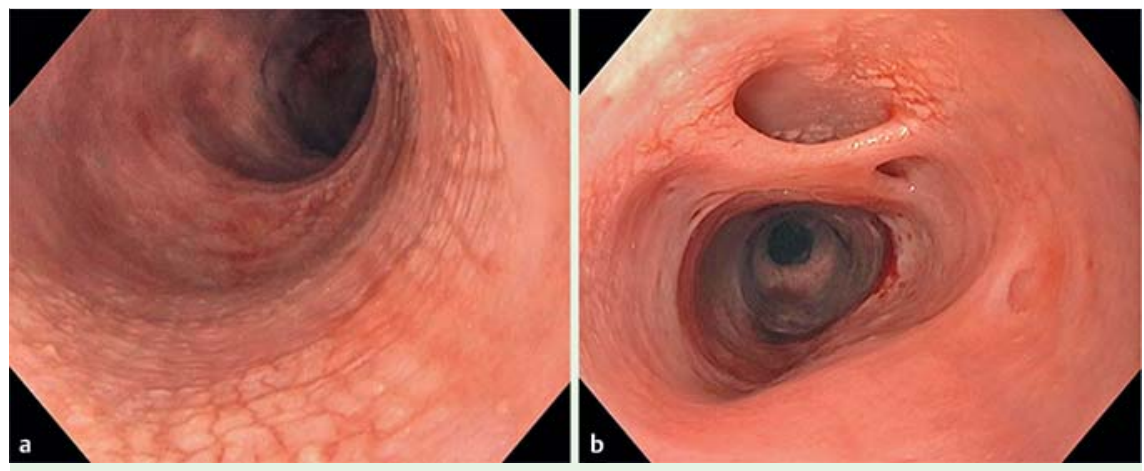

Fig. 1 Endoscopic view. a Esophageal epidermoid metaplasia characterized by multiple white patches and plaque-like lesions covering large parts of the mucosa. $\mathbf{b}$ Irregular mucosal bridges were found in the mid-portion of the esophagus linking the anterior and posterior walls transversely across the lumen.

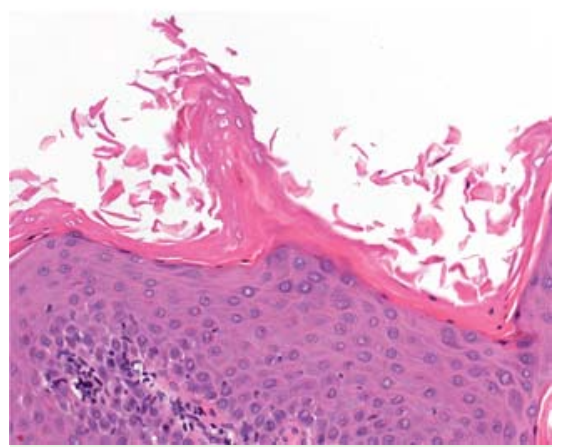

Fig. 2 Histology showed epidermoid metaplasia of the esophagus, characterized by squamous epithelium with well-developed granular cell layer, hyperorthokeratosis with focal parakeratosis, and mild peripapillary lymphocytic infiltrate (original $\times 100$ ).

Esophageal mucosal bridge formation is an uncommon condition that is believed to result from mucosa injury. Ingestion of corrosive agents, mediastinal radiation therapy, and variceal sclerotherapy have been identified as possible causes, but mucosal bridges within the esophagus have also been described in chronic inflammatory conditions such as Crohn's disease $[1,2]$.

A 53-year-old man with a long history of smoking and chronic obstructive pulmonary disease presented with dysphagia and bolus obstruction. Endoscopy revealed multiple coalescent white patches and plaque-like lesions that covered large parts of the esophageal mucosa ( $\bullet$ Fig. 1 a). In the middle portion of the esophagus, large irregular mucosal bridges were found that linked the anterior and posterior walls transversely across the lumen ( $\bullet$ Fig. $1 \mathbf{b}$ ),

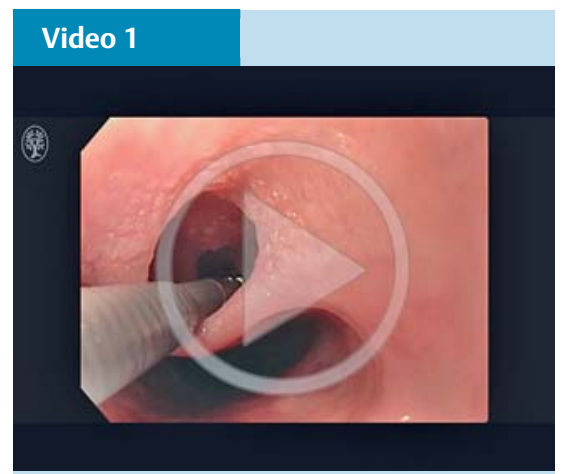

Mucosal bridging leads to double-lumen formation. The tunnel-like lumina can be intubated separately, and coalesce distally.

ultimately leading to double-lumen formation ( Video 1 ). Biopsies obtained from the white patches proved epidermoid metaplasia of the esophagus, characterized by squamous epithelium with a well-developed granular cell layer, hyperorthokeratosis with focal parakeratosis, and mild peripapillary lymphocytic infiltrate ( $\bullet$ Fig. 2).

Esophageal epidermoid metaplasia is a rare finding, which mainly affects the middle-to-distal esophagus. Cottreau et al. [3] reported a $0.19 \%$ incidence when investigating 1048 consecutive patients. The condition is characterized by plaquelike lesions with a nodular pattern on narrow-band imaging [4]. It is believed to represent an unusual response to mucosal injury. Risk factors seem to be similar to those of its oral counterpart, and associations with tobacco smoking and chronic alcohol intake have been described $[4,5]$. Differential diagnoses mainly include pill-induced esophagitis, corrosive damage, and sloughing esophagitis. Although the preneoplastic potential of the condition has not been established definitively, association with squamous dysplasia and squamous cell carcinoma has been observed [5].

In conclusion, mucosal bridges in the esophagus are rare. The association with epidermoid metaplasia, which is reported here for the first time, suggests common pathogenetic pathways related to injury and repair.

Endoscopy_UCTN_Code_CCL_1AB_2AC_3AD

\section{Competing interests: None}

\section{Elena Salamun ${ }^{1}$, Hans Peter \\ Gröchenig $^{2}$, Cord Langner ${ }^{1}$}

${ }^{1}$ Institute of Pathology, Medical University, Graz, Austria

2 Department of Internal Medicine, Krankenhaus der Barmherzigen Brüder, Academic Teaching Hospital, St. Veit/ Glan, Austria

\section{References}

1 Honda S, Sugimoto K, Iwasaki H et al. Multiple mucosal bridge formation in the esophagus in a patient with Crohn's disease. Endoscopy 1998; 30: 37-S38

2 Thomas V, Tony J, Harish $K$ et al. Endoscopic abnormalities in the oesophagus after variceal sclerotherapy - a long-term follow up study. Trop Gastroenterol 2007; 28: 24-27

3 Cottreau J, Gruchy S, Kamionek M et al. Prevalence of oesophageal epidermoid metaplasia in 1048 consecutive patients and 58 patients with squamous neoplasms. Histopathology 2016; 68: 988-995

4 Kitamura S, Okada Y, Muguruma $\mathrm{N}$ et al. Epidermoid metaplasia of the esophagus with an unusual appearance on magnification. Endoscopy 2015; 47 (Suppl. 01): E100 - E101

5 Singhi $A D$, Arnold $C A$, Crowder $C D$ et al. Esophageal leukoplakia or epidermoid metaplasia: a clinicopathological study of 18 patients. Mod Pathol 2014; 27: 38-43

\section{Bibliography}

DOI http://dx.doi.org/

10.1055/s-0042-117225

Endoscopy 2016; 48: E325

(c) Georg Thieme Verlag KG

Stuttgart · New York

ISSN 0013-726X

\section{Corresponding author}

\section{Cord Langner, MD}

Institute of Pathology

Medical University Graz

Auenbruggerplatz 25

A-8036 Graz, Austria

Fax: +43-316-38513432

cord.langner@medunigraz.at 